\title{
Implicit Racial Attitudes and Inequality in Resources Allocation
}

\author{
Yiding Lu \\ Nanjing Times College, Nanjing, China \\ Email: lyd200394@gmail.com
}

How to cite this paper: Lu, Y. D. (2021) Implicit Racial Attitudes and Inequality in Resources Allocation. Open Journal of Social Sciences, 9, 94-101.

https://doi.org/10.4236/jss.2021.911008

Received: October 8, 2021

Accepted: November 9, 2021

Published: November 12, 2021

Copyright $\odot 2021$ by author(s) and Scientific Research Publishing Inc. This work is licensed under the Creative Commons Attribution-NonCommercial International License (CC BY-NC 4.0). http://creativecommons.org/licenses/by-nc/4.0/

\begin{abstract}
Racism has been a long-standing problem for centuries, and when left unchecked, it led to far-reaching adverse consequences on social inequality. To investigate racial attitudes among Chinese adults and whether these attitudes affect Chinese people's economic decisions, we recruited a sample of 147 participants aged between $18-22$ years old. We aimed that the racial bias among Chinese young adults will be significant. The level of discrimination was measured through the Implicit Association Test (IAT). The result indicates that Chinese young adults display strong negative implicit racial bias against Black people. Critically, we also found that Chinese adults are less likely to distribute resources to Black people. This study is significant as it uses a few valid methods to test Chinese young adults' implicit attitudes toward Black people.
\end{abstract}

\section{Keywords}

Implicit Attitude, Racism, Economic Decision, Chinese Young Adult

\section{Introduction}

Inequality refers to the unequal distribution of resources and opportunities among members of society (Koh, 2020). There are wide varieties of inequality, ranging from economic inequality, educational inequality, health inequality, and many others. One salient example of inequality is racial disparities. Racial disparities permeate societies such as the United States, ranging from racial inequality in housing, wealth, educational opportunities (Green et al., 2007; see Pascoe \& Richman, 2009, for a review). For example, according to the 2016 survey of consumer finance in the United States, the median household income of White people was $\$ 170,000$, which is 10 times larger than the median Black households' 
income (McIntosh et al., 2020).

One factor that leads to economic inequality is racial bias, and a long-standing problem has existed for centuries in the United States. In today's world, racism has permeated its way to everyone, every country, and every religion. Decades of psychological studies suggest that humans judge others based on their appearances, especially skin color (Olivola and Todorov, 2010). In China, negative racial attitudes towards Black people also exist. In Guangzhou, there's a place called "Chocolate City". In this area, about 300,000 African Americans are living here. African Americans in Guangzhou were treated unequally during COVID-19, such as subject to random COVID-19 tests and be evicted from their apartment without notice (Shi, 2020).

Decades of social psychological research revealed two types of racial biases: explicit and implicit racial bias. Explicit racial biases usually involve conscious stereotyping, prejudice, and discriminatory behavior. Implicit racial biases are subconscious behavior, actions, or judgments underlying automatic evaluation called implicit attitudes (Greenwald et al., 1998). Implicit attitude is an important figure as it exists widely around humans and society. By analyzing it, scientists can dive into implicit social cognitive phenomena and reveal "true" beliefs and thoughts held by the public.

In the present study, we used the Implicit Association Test, a classic social psychological test developed by Greenwald et al. (1998), to assess implicit racial attitudes towards Blacks among a group of Chinese adults. More importantly, investigate whether implicit racial attitudes are linked to economic resource allocation, as measured in a dictator game. Daniel Kahneman first designed the dictator game; it aims to test the homo economics model of individual behavior (Kahneman et al., 1986).

\section{Methods}

\subsection{Participants}

The researchers recruited 146 participants (111 males and 33 females). The target population in this experiment is Chinese young adults aged between 18 - 22 years old. All participants are either high school or university students. 7 of them are high-school students from Nanjing Times Collage, and the rest are students from Nanjing Polytechnic Institute. All participants were recruited from snowball sampling. Snowball sampling is a technique in which participants are responsible for assisting researchers in identify potential participants.

\subsection{Procedure}

Before the actual test, the participants were informed of the experiment's purpose, procedures, and agreement to participate in the data collection. Then, the participants were asked to fill out a battery of surveys, explicit tests, and implicit tests. All task in this experiment was done on the computer. The explicit attitude 
was measured via the "dictator game". The implicit attitude was measured through the Implicit Association Test (IAT) modified by Greenwald (Greenwald et al., 2003).

\subsection{Measures}

\subsubsection{The Dictator Game}

Within the purpose of this experiment, the dictator game is about how much money you would like to share between Chinese and Blacks. There will be a button to scroll left or right to change the amount you would like to spend to the Blacks. Then, the participants need to give the reason why they make a choice. However, the question is an elective question, so the participants can choose to skip it.

\subsubsection{Implicit Association Test (IAT)}

Afterward, the main section IAT will be shown to the participants. The IAT was designed within a total of 7 blocks. In the test, the participants are first asked to distinguish between black faces and Chinese faces, positive words, and negative words. In the congruent test block, the participants are responsible for matching Chinese faces with positive words; Black faces with negative words as fast as they can. In incongruent blocks, the words will be reversed, where negative words match with Chinese faces and positive words with Black faces. Finally, the researchers will use the D score as in the previous study (Greenwald et al., 2003) to differentiate the associations of racism on Black people. For example, a relatively small D score indicates a weak association with racism on Blacks.

\subsubsection{Demographics}

Based on the purpose of controlled variables, the participants were asked to report their date of Birth, degree, and gender. Degree and gender are significant factors because then researchers are able to make further comparisons between different groups. For example, compare the result between males with females, high school with university students.

\section{Results}

\subsection{Implicit Racial Attitudes toward Black People}

To examine whether Chinese young adults show implicit attitudes towards Black people, we performed a one-sample t-test. We found that D scores are significantly larger than $0, t=12.268, p<0.05$. It suggests that Chinese young adults showed implicit bias against Black.

To further investigate how Chinese young adults show biases on Black people, and independent-sample t-test was conducted. As shown in Figure 1, no significant difference was found in males and females, $p>0.05$. These results suggest that males and females showed similar levels of implicit racial attitudes toward Black people. 


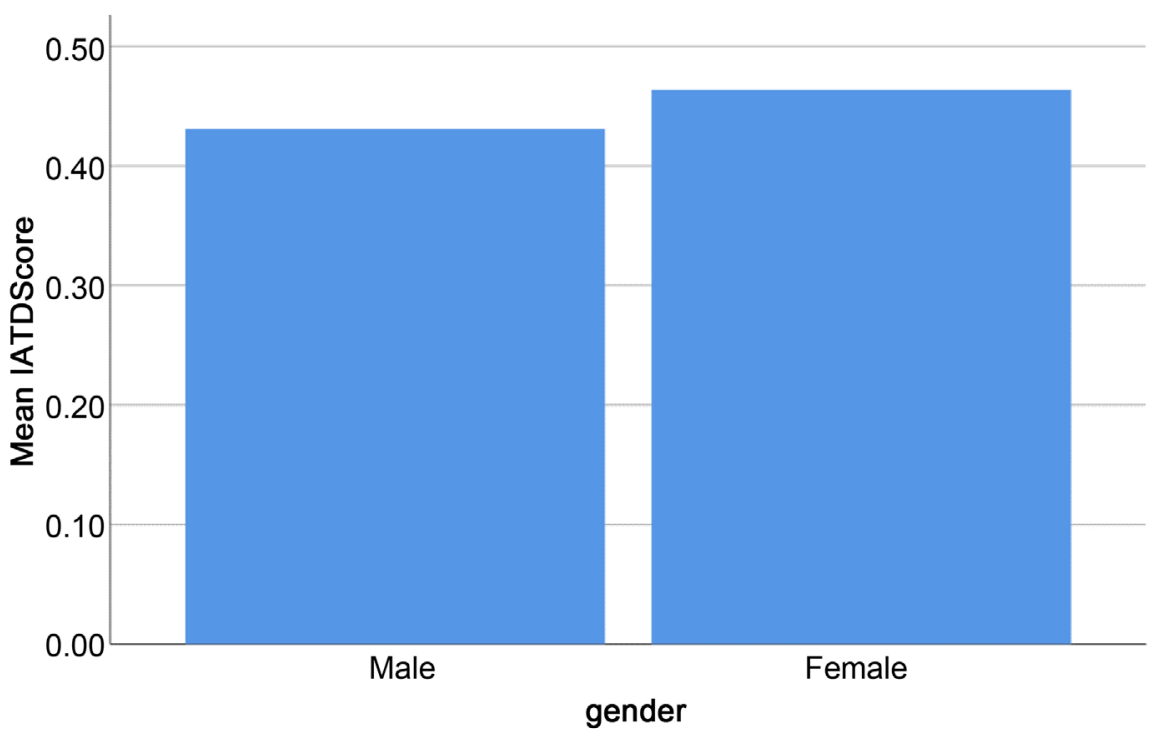

Figure 1. Mean implicit racial attitudes in male and female participants.

\subsection{Results of the Dictator Game}

To determine whether Chinese young adults distribute resources equally to Blacks and Chinese, we performed a one-sample t-test to compare their stickers given to Black to zero (chance level). We found that the average stickers given to Black people are significantly below 50, $t=-7.821, p<0.05$. These results suggest that Chinese young adults distribute less to Black people when compared to Chinese people.

To examine whether males and females distribute differently in the dictator game, we conducted another independent-sample t-test based on the dictator game. As the game is aiming for an explicit attitude of participants, it presents a different result from the result from IAT. As shown in the second table, both the second column and fifth column of p-value in the table are less than 0.05 , which suggests that the difference between the two independent groups is significant. As shown in Figure 2, there is a mean difference between the two groups. The value presents that females are sharing $\$ 10.91$ more money with Black people than males. The outstanding difference suggests that females tend to have less bias on Black people as they are sharing more money with the Blacks in the dictator game.

\subsection{Correlation between Implicit D Scores and Resource Allocation}

To examine the relationship between the result of IAT and the dictator game, we performed a correlational analysis. We found a significant positive correlation between IAT D score and the amount of stickers (out of 100) shared to Blacks, $r=0.188, p<0.05$ (Table 1). The positive correlation indicates that the stronger implicit biases people hold for Blacks, the more money they would like to distribute. 




Figure 2. Mean explicit racial attitudes in male and female participants.

Table 1. Correlation between implicit racial bias and resources allocation.

\begin{tabular}{ccc}
\hline & Implicit racial bias scores & Resource allocation \\
\hline $\begin{array}{c}\text { Implicit racial bias scores } \\
\text { Resource allocation }\end{array}$ & $0.188^{*}$ \\
\hline
\end{tabular}

Note. ${ }^{\star}$ represents $p<0.05$.

\section{Discussion}

The present study aims to assess implicit racial attitudes towards blacks among a group of Chinese young adults. More importantly, it aims to investigate whether implicit racial attitudes are linked to economic resource allocation. As measured in an IAT, we found most Chinese young adults have a significant implicit racial bias toward black people. Results from the dictator game indicated that participants were sharing less with blacks, showing racial biases in resources allocation. Crucially, we also found a positive correlation between the IAT and dictator games, suggesting that Chinese young adults with stronger implicit racial bias against Blacks distributed more resources to the Blacks.

Our implicit results are consistent with previous studies on IAT. In a similar study, Greenwald, in his research in 1998 (Greenwald et al., 1998), conducted an experiment to investigate the racial stereotypes on Whites and Blacks by using an implicit association test. The result suggests White Americans are more likely to connect Whites with positive words and Blacks with negative words. It is significant as the experiment presents the racial stereotypes that existed among society. In another study conducted by Qian et al. (Qian et al., 2016) designed an experiment to investigate the implicit racial bias towards Blacks among aged 3 5 years old Chinese children and adults. The results present that both Chinese children and adults tend to perform a bias on racial Blacks, but not for Whites. Thus, our result is in line with what other researchers found in the previous 
study, where Chinese adults have a significant bias on Blacks. One possibility is due to Chinese news reports depicting Blacks in a negative tone. For example, during the COVID-19 pandemic, there were many hostile attacks against Asian people in the United States. Chinese news websites had posted much news about it online. "Black men who attacked Chinese with heavy punches are repeat offenders: 8 arrests for assaults and arson in 2020" (Wang, 2021); these attacks on Chinese by Black people had formed many Chinese's negative stereotypes of Blacks as most of them have never been with black people.

The result of the dictator game suggests that participants allocated more resources (money) to the Chinese and less to Blacks. This result is also consistent with previous findings. According to Greenwald et al. (Greenwald et al., 1998), the researchers identified the terms ingroup and outgroup. Participants are more likely to c study, as the participants tend to allocate more resources (money) to Chinese. In 2013, Chen, Zhu, and Chen conducted an experiment to investigate rural area Chinese children's altruistic behavior in the dictator game (Chen et al., 2013). The result suggests the ingroup behavior as children are sharing more with friends rather than friends (the recipients are rather friends or strangers). Additionally, the study also presents that children from low income families are more prosocial than children from high-income families. Moreover, the researchers gathered 111 males and 33 females as participants, by comparing the result between genders, females are sharing $32 \%$ more money than males to the black people, which indicates that females are more prosocial. However, both of the mean amounts that share with Blacks for males and females had not passed 50 , which suggests the racial bias on black people.

Last and more interestingly, we found that there is a positive relationship between the two tests, which suggests that people with stronger biases tend to give more to Black people. This finding indicates that there might not be a direct connection between implicit and explicit attitudes or implicit attitudes and their actual behaviors. Supporting this argument, Greenwald et al. have a similar conclusion with this experiment, as there is no significant correlation relationship between implicit and explicit attitudes (Greenwald et al., 1998). Moreover, in the same study that Greenwald conducted, he found that the significance of implicit bias is quite stable, but for explicit, it's unstable. Thus, it indicates that implicit bias is able to decrease the distribution of consciousness, which measures people's unconscious attitudes more directly and correctly. One reason might be when the participants did the IAT, and they have less time to consider which measures their action without consciousness. However, in the dictator which is the economic resources allocation test, the participants had a much longer time to consider whether their answer is prosocial, which might explain why the correlation between IAT and dictator game is positive.

There are few limitations to acknowledge. Firstly, the sample size of the experiment is too small, and there are only 144 persons. All participants arelfrom high-school or Universities in Nanjing, only from one city and two specific 
schools. Thus, it cannot represent the Chinese young adult as a whole. For example, maybe young adults from Guangzhou will have a relatively weaker racial bias on Black people, as the population of Blacks in Guangzhou is higher, the citizens in Guangzhou might have a better impression of them as some of them might be familiar with Black people. Thus, the result is not valid when taking into the investigation of one country's young adult.

Secondly, the sampling method is not valid in some ways. As is a voluntary test online, gender is not controlled. According to the results, there are a total of 144 participants but 111 males and only 33 females, which is significantly unbalanced. Moreover, the experiment had investigated specifically the differences between genders. As it was not balanced, the result might not be valid, because the sample from females was not enough to fairly compare with the males.

To conclude, the present experiment investigates Chinese young adults' implicit attitudes toward Black people. The results illustrate that the negative stereotypes of Black people existed among young adults in China. However, in the future, the researcher should expand its sample size in order to modify the research to be more precise and valid.

\section{Conflicts of Interest}

The author declares no conflicts of interest regarding the publication of this paper.

\section{References}

Chen, Y., Zhu, L., \& Chen, Z. (2013). Family Income Affects Children's Altruistic Behavior in the Dictator Game. PLoS ONE, 8, e80419.

https://doi.org/10.1371/journal.pone.0080419

Green, A. R., Carney, D. R., Pallin, D. J., Ngo, L. H., Raymond, K. L., Iezzoni, L. I., \& Banaji, M. R. (2007). Implicit Bias among Physicians and Its Prediction of Thrombolysis Decisions for Black and White Patients. Journal of General Internal Medicine, 22, 1231-1238. https://doi.org/10.1007/s11606-007-0258-5

Greenwald, A. G., McGhee, D. E., \& Schwartz, J. L. (1998). Measuring Individual Differences in Implicit Cognition: The Implicit Association Test. Journal of Personality and Social Psychology, 74, 1464-1480. https://doi.org/10.1037/0022-3514.74.6.1464

Greenwald, A. G., Nosek, B. A., \& Banaji, M. R. (2003). Understanding and Using the Implicit Association Test: I. An Improved Scoring Algorithm. Journal of Personality and Social Psychology, 85, 197-216. https://doi.org/10.1037/0022-3514.85.2.197

Kahneman, D., Knetsch, J. L., \& Thaler, R. H. (1986). Fairness and the Assumptions of Economics. The Journal of Business, 59, S285-S300. https://doi.org/10.1086/296367 http://www.jstor.org/stable/2352761

Koh, S. Y. (2020). Inequality. International Encyclopedia of Human Geography (Second Edition), 269-277. https://doi.org/10.1016/B978-0-08-102295-5.10196-9 https://www.sciencedirect.com/science/article/pii/B9780081022955101969

McIntosh, K., Moss, E., Nunn, R., \& Shambaugh, J. (2020, February 27). Examining the Black-White Wealth Gap. Brookings.

https://www.brookings.edu/blog/up-front/2020/02/27/examining-the-black-white-weal th-gap/ 
Olivola, C. Y., \& Todorov, A. (2010). Elected in 100 Milliseconds: Appearance-Based Trait Inferences and Voting. Journal of Nonverbal Behavior, 34, 83-110. https://doi.org/10.1007/s10919-009-0082-1

Pascoe, E. A., \& Richman, L. S. (2009). Perceived Discrimination and Health: A Meta-Analytic Review. Psychological Bulletin, 135, 531-554. https://doi.org/10.1037/a0016059

Qian, M. K., Heyman, G. D., Quinn, P. C., Messi, F. A., Fu, G., \& Lee, K. (2016). Implicit Racial Biases in Preschool Children and Adults from Asia and Africa. Child Development, 87, 285-296. https://doi.org/10.1111/cdev.12442

Shi, J. (2020, April 11). US Warns African-Americans to Avoid Guangzhou Due to Discrimination Fears. South China Morning Post. https://www.scmp.com/news/china/society/article/3079497/us-warns-african-american s-avoid-guangzhou-after-reports-black

Wang, H. (Ed.) (2021, June 2). 重拳袭击华裔的黑人男子是惯犯: 2020 年因袭击、纵火 被捕 8 次.

https://ishare.ifeng.com/c/s/v002PxLFYkzeOuGs3BLGu3vvNI2dnKyDcPrQr5YHzmKs 4IE 